\title{
Air enema versus barium enema in intussusception: an overview
}

\author{
Lujain Al-Mubarak ${ }^{1}$, Eman Alghamdi ${ }^{1}$, Saad Alharbi ${ }^{2}$, Hidayah Almasoud ${ }^{3}$, Naseem Al-Ali ${ }^{3}$, \\ Shrooq Mujurdy ${ }^{4}$, Amro Alamro ${ }^{5}$, Albatoul Nagadi ${ }^{6}$, Alhareth Alsharif ${ }^{7}$, Saad Almugbel ${ }^{8}$
}

College of Medicine, ${ }^{1}$ Imam Abdulrahman Bin Faisal University, Dammam, Saudi Arabia; ${ }^{2}$ Arabian Gulf University, Manama, Bahrain; ${ }^{4}$ Taif University, Taif, Saudi Arabia; ${ }^{5}$ Qassim University, Qassim, Saudi Arabia; ${ }^{6}$ King Abdulaziz University, Jeddah, Saudi Arabia; ${ }^{7}$ Ibn Sina National College, Jeddah, Saudi Arabia; ${ }^{8}$ Imam Muhammad ibn Saud Islamic University, Riyadh, Saudi Arabia

${ }^{3}$ Department of Pediatrics, Maternity and Children Hospital, Al-Ahsa, Saudi Arabia

Received: 22 March 2018

Accepted: 10 April 2018

\section{*Correspondence:}

Dr. Lujain Al Mubarak,

E-mail: lujain.21@hotmail.com

Copyright: $\odot$ the author(s), publisher and licensee Medip Academy. This is an open-access article distributed under the terms of the Creative Commons Attribution Non-Commercial License, which permits unrestricted non-commercial use, distribution, and reproduction in any medium, provided the original work is properly cited.

\begin{abstract}
Intussusception is a common cause of intestinal obstruction in paediatric population. It is a medical emergency that necessitates prompt reduction of intussuscepting bowel. If left untreated, intussusception can be fatal in a couple of days. The mainstay treatment of intussusception is enema reduction. Both barium and air enema reduction techniques are successful and acceptable strategies for management of intussusception in children. The use of air reduction is currently growing for its safety. Air reduction is associated with higher success rates, less risk for perforation, and less risk for peritoneal contamination than barium reduction. Air reduction generates higher intraluminal pressure during the reduction procedure thus making it faster and more effective. Barium reduction, on the other side, has a diagnostic potential and can better detect pseudo-reduction after management of intussusception. It is easier to perform and more familiar for most of the radiologists than air reduction. To date, both techniques are used, and the choice depends largely on clinical practice, institutional guidelines, and radiologists' preference. This article aims at differentiating between the two types of reduction regarding the technique, advantages, disadvantages, success rates, recurrence rates, and complications rates.
\end{abstract}

Keywords: Intussusception, Enema, Barium, Barium enema, Air enema

\section{INTRODUCTION}

Intussusception is a common cause of intestinal obstruction in pediatric population. It commonly affects infants between the age of 4 and 10 months, and it is considered the second most common cause of bowel obstruction after pyloric stenosis at this age. ${ }^{1}$ Intussusception refers to the invagination of a loop of bowel within another more distal one. During the process of invagination, the intestinal loop pulls along its arterial supply making it vulnerable to ischemia and perforation. ${ }^{2}$ Ileum is the most common loop to be affected in intussusception and it invaginates into the cecum through the ileocecal valve. Intussusception is a medical emergency that necessitates prompt reduction of intussuscepting bowel. If left untreated, intussusception can be fatal in a couple of days. Mortality results from intestinal ischemia, perforation, septic peritonitis, and septic shock. ${ }^{3}$ Proper early management, however, decreases the mortality rate to less than $1 \% .^{4}$

Successful management of intussusception imposes early diagnosis, adequate fluid therapy, and early reduction of the invaginating intestinal loops. ${ }^{2}$ The gold standard treatment of intussusception is enema reduction. ${ }^{5}$ Both air enema and barium enema are commonly utilized and 
equally acceptable during the reduction process. This article aims at comparing the advantages, disadvantages, and outcomes of both enemas in intussusception reduction process.

\section{EPIDEMIOLOGY}

Typically, intussusception presents in infants and children between 6 months and 3 years, and it is the second most common cause of bowel obstruction in this age group after pyloric stenosis. The mean age of intussusception was reported to be 2.7 years in one study in Switzerland. ${ }^{6}$ It is estimated that more than two-thirds of the cases presents before the age of 12 months and up to $90 \%$ presents before the age of 24 months. ${ }^{7}$

The actual prevalence of intussusception is not known, and the incidence is variable among different countries and cities. In the United States (US), the incidence of intussusception is about 1 case per 2000 live births. ${ }^{8}$ In Switzerland, a population surveillance conducted from April 2003 to March 2006 reported the incidence of intussusception was 38 cases per 100,000 live births in the first year of life, 31 cases per 100,000 live births in the second year, and 26 cases per 100,000 live births in the third year of life. The incidence among older children was less than half of these values. ${ }^{6}$ In united kingdom (UK), the reported incidences ranged from 1.6 to 4 cases per 1000 live births. ${ }^{9}$ Intussusception is more prevalent among males in children with a male to female ratio of $3: 1$. This difference is even more evident in older children i.e. male children above the age of 4 years are eight times more vulnerable to intestinal intussusception than females at this age. ${ }^{10,11}$ Despite being common is infants and young children, intussusception should be considered in children outside this age group. Some case studies reported intussusception during neonatal period, and many researchers reported the condition after 5 and even 10 years of age. ${ }^{6,7}$

In children younger than 5 years, intussusception accounts for up to $25 \%$ of all cases of abdominal surgical emergencies. ${ }^{2}$ Intussusception results in about 55 per 100,000 annual hospitalizations in the United States (U.S.). ${ }^{1}$

\section{DIAGNOSIS OF INTUSSUSCEPTION}

Clinically, intussusception is considered in young infants, at typical age group of the disease, who experience signs of intestinal obstruction. Intussusception often follows upper respiratory tract infection, and thus a viral aetiology is highly suggestive specifically Rotavirus. ${ }^{12,13}$ Infants present initially with non-bilious reflexive vomiting that subsequently becomes bilious when intestinal obstruction takes place. Abdominal pain accompanies the vomiting and is usually colicky, intermittent, and severe in intensity. Diarrhoea is always an early sign of intussusception and is characterized by mucous bloody stools. As the condition progress, the infant becomes lethargic, confused, and toxic. Palpable right hypochondrial sausage-like abdominal mass is the hallmark physical finding on examination. The right lower abdominal quadrant is often empty (Dance sign) and abdominal distension is encountered when bowel obstruction occurs. ${ }^{1,2,10,11}$

Various imaging studies can be diagnostic for intestinal intussusception. Plain abdominal X-ray radiography can be diagnostic in $60 \%$ of the cases where it shows soft tissue density in right upper abdominal quadrant and air in right lower quadrant. Air-fluid level and dilatation of the small intestine occur later. ${ }^{14}$ Abdominal ultrasonography has a sensitivity of $97.9 \%$ and specificity of $97.8 \%$ in detecting intussusception. It reveals a characteristic target or pseudo-kidney sign. ${ }^{15}$ The most reliable method for making the diagnosis of intussusception in children is contrast enema, either barium or air. ${ }^{16}$ Contrast enema has the advantages of being quick, reliable, and potentially therapeutic for children with intussusception. ${ }^{16}$

\section{BARIUM VERSUS AIR ENEMA FOR INTUSSUSCEPTION REDUCTION}

Reduction is the mainstay treatment for intussusception in children. It can be performed non-operatively using enemas or operatively using open or laparoscopic surgery. Non-operative reduction is the role except in cases with any evidence of intestinal perforation and peritonitis. Other contraindications include small-bowel intussusception, intussusception in neonates, and intussusception in children with haemophilia, HSP, Peutz-Jegher syndrome, or malignancies. It can be performed under fluoroscopic or ultrasonographic guidance using hydrostatic enemas (e.g. water-soluble contrast or barium) or pneumatic (e.g. air insufflation). ${ }^{17}$ Reduction is considered successful when the air or barium is seen on ultrasound refluxing back into the ileum through the ileocecal junction. However, such reflux may not be visualized in cases of competent or oedematous ileocecal valve. Therefore, clinical improvement is a hallmark of successful reduction in those patients. ${ }^{16}$

Both air and barium reduction are used and equally acceptable in intussusception reduction. However, the use of air reduction is growing. ${ }^{18}$ The choice of the reduction strategy is highly subjective, variable and depends on regional practice, organisational protocols, and radiologists' preferences. To date, no clear guidelines are available to help this choice. Results from a recent comprehensive meta-analysis, including included 32451 patients who had enema reduction from 1966 to 2013, showed that air enema reduction had a higher success rates than barium enema. ${ }^{19}$ The mean success rate was $82.7 \%$ for air enema reduction and $69.6 \%$ for barium enema reduction. The recurrence rate 48 hours after enema reduction was not statistically significant between both approaches. ${ }^{19}$ 


\section{Air enema reduction}

Air reduction is one technique for management of intussusception in children. It is carried out through introducing $\mathrm{CO}_{2}, \mathrm{O}_{2}$, or air into the gastrointestinal tract through a rectal catheter. The pressure recommended for air insufflation in air-enema should be below $120 \mathrm{~cm}$ $\mathrm{H}_{2} \mathrm{O}$, pressures between $80-120 \mathrm{~cm} \mathrm{H}_{2} \mathrm{O}$ are commonly used. The main advantages of this technique are low radiation exposure and low risk of peritonitis if perforation occurred. ${ }^{20}$ They are also faster, safer, and cheaper than liquid reduction techniques. Most of the air enema reduction strategies are closed-systems that use inflated balloon catheter to ensure reliable tight seal distally at the anus. ${ }^{21}$ This ensures maintained elevation of intra-luminal pressure and subsequently shorter time for the procedure. Using plastic catheters or manual squeezing of buttocks against catheters are not effective in prevention of air leakage. Air reduction is not preferred in cases of small bowel or prolapsing intussusception as it has low success rates in these conditions. ${ }^{22}$

\section{Barium enema reduction}

Barium reduction is one of the non-operative methods for management of intussusception. Barium enema delivery system depends on hydrostatic pressure from a bag containing barium with elevated pressure. This system is subjected to bidirectional flow and thus generates a lower intraluminal pressure than that generated in air reduction systems. The pressure recommended for barium-enema should not exceed $100 \mathrm{~cm}$ above the buttock level. Using an inflated balloon is also beneficial in this system to minimize air leakage and to direct the flow in a single direction from the delivery system to the intestine. ${ }^{18}$

One of the advantages of barium enemas over air enemas is that they are potentially diagnostic and can visualise the invaginating intestinal loops in cases with dilated gasfilled intestinal loops. Other advantages include the ability of the barium enemas to better identify the pathologic lead points of the intussusception than airsystems and to document pseudo-reduction. ${ }^{21}$ Most radiologists are more familiar with barium enema than air enema and thus prefer its use. On the other hand, barium enema delivery systems are associated with higher risk of septic peritonitis and electrolyte disturbance if intestinal perforation occurred. ${ }^{17}$ Success rate of barium reduction of intussusception varies widely from 40-90\% among studies. ${ }^{10}$ This variability is attributed to many factors either related to the patient, the radiologist, or the institution.

\section{Air versus barium enema reduction}

Many studies have done conducted to differentiate between air and barium enema reduction as regards the success, recurrence, and complications rates. Table 1 summarizes the differences between the two techniques regarding advantages, disadvantages, techniques, success rates, recurrence rates, perforation rates, and peritonitis rates.

Table 1: Summary of the differences between barium and air reduction techniques.

\begin{tabular}{|c|c|c|}
\hline & Barium Enema Reduction & Air Enema Reduction \\
\hline \multicolumn{3}{|l|}{ Technique } \\
\hline - $\quad$ Substance used & Barium & Air, $\mathrm{CO}_{2}, \mathrm{O}_{2}$ \\
\hline - $\quad$ Pressure & $<100 \mathrm{~cm}$ above buttock level & $<120 \mathrm{~cm} \mathrm{H}_{2} \mathrm{O}$ \\
\hline - $\quad$ Delivery system & Bidirectional - less sealed & Better seal \\
\hline - $\quad$ Agent leakage & +++ & + \\
\hline Advantages & $\begin{array}{ll}- & \text { Diagnostic and therapeutic } \\
- & \text { Better detection of lead points } \\
- & \text { Familiar among radiologists }\end{array}$ & $\begin{array}{ll}- & \text { Safer } \\
- & \text { Faster } \\
- & \text { Better seal, less air leakage } \\
- & \text { Less risk for peritoneal contamination if } \\
& \text { perforation occurred }\end{array}$ \\
\hline Disadvantages & 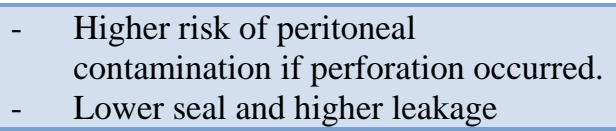 & $\begin{array}{l}\text { Therapeutic only (cannot be used for } \\
\text { diagnosis) } \\
\text { - } \quad \text { Cannot detect lead points. }\end{array}$ \\
\hline Success rate & Lower $(69.6 \%)$ & Higher $(82.7 \%)$ \\
\hline Recurrence rate & Same & Same \\
\hline Perforation rate & Slightly higher & Slightly lower \\
\hline $\begin{array}{l}\text { Risk of peritoneal } \\
\text { contamination }\end{array}$ & +++ & + \\
\hline Current use & Declining & Growing \\
\hline
\end{tabular}

\section{Success rates}

Beres et al, in their meta-analysis studying the pneumatic versus barium reduction, reported higher success rates with air reduction. ${ }^{22}$ They stated that there was no significant difference between both approaches as regards the perforation rate. In agreement with this, other studies reported that the higher success rate encountered among patients who underwent air reduction could be attributed to the higher pressures used in these delivery systems. ${ }^{23}$ 
Other researchers stated that air enemas have higher success rates than barium enemas only if they were performed under fluoroscopic guidance. However, no statistically significant difference was found between air and barium enema when ultrasound guidance was used. ${ }^{21}$

Barium enemas were reported to have a significant advantage not found in air enemas. They were associated with higher rates of visualization of lead points during intussusception reduction than air enemas. Lead points were identified in $6.3 \%$ and $2.0 \%$ in barium reduction and air reduction, respectively. ${ }^{19}$

A recent meta-analysis published in 2015 revealed that the considerably higher success rates of air enema than barium enema for intussusception reduction was independent of any confounding factors including the hospital type, the country, the year of publication, the design of the study (retrospective or prospective).

\section{Recurrence rates}

Gray et al explored the recurrence rate after air and barium enema and they reported no significant difference between both techniques. ${ }^{5}$ Similarly, many studies including meta-analysis reviews and large randomised control studies agreed that the 48-hour recurrence rate was closely similar between air and barium enemas. ${ }^{19,23}$ Matthew et al, in their meta-analysis, stated that the recurrence rates after barium enema reduction are slightly higher than those after air reduction techniques. ${ }^{5}$ The overall recurrence was $12.7 \%$ and $7.5 \%$ among barium reduction and air reduction, respectively. The 24-hour reduction rate was $3.9 \%$ in patients who underwent barium reduction and $2 \%$ among those who had air reduction technique. ${ }^{5}$ Similarly, Narimis et al reported an overall recurrence rate of $15.8 \%$ after barium reduction and $11.4 \%$ after air reduction. ${ }^{24}$ However, the difference between both approaches was insignificant $(\mathrm{p}=0.08)$.

\section{Perforation rates}

Results from literature studies are conflicting about the perforation rates of air and barium enemas. Some researchers reported no statistically significant difference in perforation rates among the two approaches. 18,19,21,22 $^{2}$ Others, however, stated that air enemas result in smaller perforations and less peritoneal contamination than barium studies. $^{25,26}$ Perforation rate can be affected by multiple factors including the degree of intestinal ischemia, intestinal wall friability, the technique used, and the pressure generated during the reduction procedures. Most of these factors were not considered in the literature and thus the reliability of the results cannot be guaranteed.

\section{CONCLUSION}

Both barium and air reduction techniques are successful and acceptable strategies for management of intussusception in children. The use of air reduction is currently growing for its safety. Air reduction is associated with higher success rates, less risk for perforation, and less risk for peritoneal contamination than barium reduction. Air reduction generates higher intraluminal pressure during the reduction procedure thus making it faster and more effective. Barium reduction, on the other side, has a diagnostic potential and can better detect pseudo-reduction after management of intussusception. It is easier to perform and more familiar for most of the radiologists than air reduction. To date, both techniques are used and the choice depends largely on clinical practice, institutional guidelines, and radiologists' preference.

\section{Funding: No funding sources \\ Conflict of interest: None declared \\ Ethical approval: Not required}

\section{REFERENCES}

1. Lehnert T, Sorge I, Till H, Rolle U. Intussusception in children-clinical presentation, diagnosis and management. Int J Colorectal Dis. 2009;24(10):1187-92.

2. Jiang J, Jiang B, Parashar U, Nguyen T, Bines J, Patel MM. Childhood Intussusception: A Literature Review. PLoS One. 2013;8(7):1-14.

3. Traore D, Sissoko F, Ongoiba N, Traore I, Traore AK, Koumare AK. Adult intussusception: diagnostic pitfalls, morbidity and mortality in a developing country. J Visc Surg. 2012;149(3):e2114.

4. Desai R, Curns AT, Patel MM, Parashar UD. Trends in intussusception-associated deaths among US infants from 1979-2007. J Pediatr. 2012;160(3):45660.

5. Gray MP, Li S-H, Hoffmann RG, Gorelick MH. Recurrence Rates After Intussusception Enema Reduction: A Meta-analysis. Pediatrics. 2014;134(1):110-9.

6. Buettcher M, Baer G, Bonhoeffer J, Schaad UB, Heininger U. Three-Year Surveillance of Intussusception in Children in Switzerland. Pediatrics. 2007;120(3):473-80.

7. Mandeville K, Chien M, Willyerd FA, Mandell G, Hostetler MA, Bulloch B. Intussusception: Clinical presentations and imaging characteristics. Pediatr Emerg Care. 2012;28(9):842-4.

8. Johnson B, Gargiullo P, Murphy TV, Parashar UD, Patel MM. Sociodemographic and dietary risk factors for natural infant intussusception in the United States. J Pediatr Gastroenterol Nutr. 2010;51(4):458-63.

9. Huppertz HI, Soriano-Gabarró M, Grimprel E, Franco E, Mezner Z, Desselberger U, et al. Intussusception Among Young Children in Europe. Pediatr Infect Dis J. 2006;25(Supplement):S22-9.

10. Waseem M, Rosenberg HK. Intussusception. Pediatr Emerg Care. 2008;24(11):793-800.

11. Columbani PM, Scholz S. Paediatric Surgery. 7th ed. In: Coran AG, Adzick NS, Krummel TM, 
Laberge JM, Shamberger RC, Caldamone AA. Editors, Elsevier Saunders; 2012: 1093-1110.

12. Bines J. Intussusception and rotavirus vaccines. Vaccine. 2006;24(18):3772-6.

13. Weintraub ES, Baggs J, Duffy J, Claudia Vellozzi, Belongia EA, Irving S, et al. Risk of Intussusception after Monovalent Rotavirus Vaccination. N Engl J Med. 2014;370(6):513-9.

14. Morrison J, Lucas N, Gravel J. The Role of Abdominal Radiography in the Diagnosis of Intussusception When Interpreted by Pediatric Emergency Physicians. J Pediatr. 2009;155(4):5569.

15. Hryhorczuk AL, Strouse PJ. Validation of US as a first-line diagnostic test for assessment of pediatric ileocolic intussusception. Pediatr Radiol. 2009;39(10):1075-9.

16. Shekherdimian S, Lee SL, Sydorak RM, Applebaum H. Contrast enema for pediatric intussusception: is reflux into the terminal ileum necessary for complete reduction? J Pediatr Surg. 2009;44(1):24750 .

17. Ko HS, Schenk JP, Tröger J, Rohrschneider WK. Current radiological management of intussusception in children. Eur Radiol. 2007;17(9):2411-21.

18. ACR-SPR Committee. ACR-SPR practice parameter for the performance of pediatric fluoroscopic contrast enema examinations. Pract Parameters Tech Stand. 2016;1076:1-10.

19. Sadigh G, Zou KH, Razavi SA, Khan R, Applegate KE. Meta-analysis of air versus liquid enema for intussusception reduction in children. Am J Roentgenol. 2015;205(5):W542-9.

20. Bratton SL, Haberkern CM, Waldhausen JHT, Sawin RS, Allison JW. Intussusception: Hospital Size and Risk of Surgery. Pediatrics. 2001;107(2):299-303.
21. Betz BW, Hagedorn JE, Guikema JS, Barnes CL. Therapeutic enema for pediatric ileocolic intussusception: Using a balloon catheter improves efficacy. Emerg Radiol. 2013;20(5):385-91.

22. Beres AL, Baird R. An institutional analysis and systematic review with meta-analysis of pneumatic versus hydrostatic reduction for pediatric intussusception. Surg (United States). 2013;154(2):328-34.

23. Xie X, Wu Y, Wang Q, Zhao Y, Chen G, Xiang B. A randomized trial of pneumatic reduction versus hydrostatic reduction for intussusception in pediatric patients. Journal of Pediatric Surgery. 2017.

24. Niramis R, Watanatittan S, Kruatrachue A, Anuntkosol M, Buranakitjaroen V, Rattanasuwan T, et al. Management of recurrent intussusception: Nonoperative or operative reduction? J Pediatr Surg. 2010;45(11):2175-80.

25. Shiels WE, Kirks DR, Keller GL, Ryckman FR, Daugherty CC, Specker BL, et al. John Caffey Award. Colonic perforation by air and liquid enemas: comparison study in young pigs. Am J Roentgenol. 1993;160(5):931-5.

26. Hernanz-Schulman M, Foster C, Maxa R, Battles G, Dutt P, Stratton C, et al. Experimental study of mortality and morbidity of contrast media and standardized fecal dose in the peritoneal cavity. Pediatr Radiol. 2000;30(6):369-78.

Cite this article as: Al-Mubarak L, Alghamdi E, Alharbi S, Almasoud H, Al-Ali N, Mujurdy S, et al. Air enema versus barium enema in intussusception: an overview. Int J Community Med Public Health 2018;5:1679-83. 